\title{
Identification of earthquake precursors in the hydrogeochemical and geoacoustic data for the Kamchatka peninsula by flicker-noise spectroscopy
}

\author{
G. V. Ryabinin ${ }^{1}$, Yu. S. Polyakov ${ }^{2}$, V. A. Gavrilov ${ }^{3}$, and S. F. Timashev ${ }^{4,5}$ \\ ${ }^{1}$ Kamchatka Branch, Geophysical Survey of Russian Academy of Sciences, Petropavlovsk-Kamchatsky, Russia \\ ${ }^{2}$ USPolyResearch, Ashland, PA, USA \\ ${ }^{3}$ Institute of Volcanology and Seismology, Far Eastern Branch of the Russian Academy of Sciences, \\ Petropavlovsk-Kamchatsky, Russia \\ ${ }^{4}$ Institute of Laser and Information Technologies, Russian Academy of Sciences, Troitsk, Moscow Region, Russia \\ ${ }^{5}$ Karpov Institute of Physical Chemistry, Moscow, Russia
}

Received: 29 October 2010 - Revised: 17 December 2010 - Accepted: 4 January 2011 - Published: 18 February 2011

\begin{abstract}
A phenomenological systems approach for identifying potential precursors in multiple signals of different types for the same local seismically active region is proposed based on the assumption that a large earthquake may be preceded by a system reconfiguration (preparation) on different time and space scales. A nonstationarity factor introduced within the framework of flicker-noise spectroscopy, a statistical physics approach to the analysis of time series, is used as the dimensionless criterion for detecting qualitative (precursory) changes within relatively short time intervals in arbitrary signals. Nonstationarity factors for chlorine-ion concentration variations in the underground water of two boreholes on the Kamchatka peninsula and geacoustic emissions in a deep borehole within the same seismic zone are studied together in the time frame around a large earthquake on 8 October 2001. It is shown that nonstationarity factor spikes (potential precursors) take place in the interval from 70 to 50 days before the earthquake for the hydrogeochemical data and at 29 and 6 days in advance for the geoacoustic data.
\end{abstract}

\section{Introduction}

Earthquake prediction within a time frame of several months to less than an hour before the catastrophic event, which is often referred in literature as "short-term" prediction, has been a subject of extensive research studies and controversial

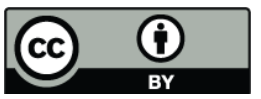

Correspondence to: Yu. S. Polyakov (ypolyakov@uspolyresearch.com) debates, both in academia and mass media, in the past two decades (Geller, 1997; Geller et al., 1997; Wyss et al., 1997; Uyeda et al., 2009; Cicerone et al., 2009). One of the key areas in this field is the study of earthquake precursors, physical phenomena that reportedly precede at least some earthquakes. The precursory signals are usually grouped into electromagnetic, hydrological/hydrochemical, gasgeochemical, geodetic, and seismic (Geller, 1997; Hartmann and Levy, 2005; Uyeda et al., 2009; Cicerone et al., 2009). Electromagnetic precursory signals are further classified into signals believed to be emitted from within focal zones, such as telluric and magnetic field anomalies, and radio waves over epicentral regions (Uyeda et al., 2009). The localized changes in electric and magnetic fields that reportedly accompany some seismic events span a wide range of frequencies, including ULF, VLF, ELF and RF fields, and were observed in the time frame from 2-3 years to dozens of minutes prior to an earthquake (Cicerone et al., 2009; Uyeda et al., 2009). Hydrological/hydrochemical precursory signals include water level or quality changes weeks, days, or hours prior to a number of earthquakes, groundwater temperature changes, and variations in the concentrations of dissolved ions like chlorine or magnesium usually in a time frame of months to days before an earthquake (Hartmann and Levy, 2005; Cicerone et al., 2009; Du et al., 2010). Gasgeochemical precursory signals comprise numerous anomalous gas emission observations, the majority of which were reported for the concentration of radon gas in the earth (Hartmann and Levy, 2005; Cicerone et al., 2009). More than 100 studies show that changes in radon exhalation from the earth's crust precede a number of earthquakes by months, weeks, or days (Cicerone et al.,

Published by Copernicus Publications on behalf of the European Geosciences Union. 
2009). Geodetic signals mostly include surface deformations (tilts, strains, strain rate changes) over distances of tens of kilometers that precede some major earthquakes by months to days (Cicerone et al., 2009). Seismic precursory signals encompass foreshocks that typically take place less than 30 days before the main shock and high-frequency (acoustic emission) and very low-frequency precursory signals that are not detected by conventional seismographs (Ihmle and Jordan, 1994; Reasenberg, 1999; Gordienko et al., 2008; Gavrilov et al., 2008). Another promising type of possible precursory signals is anomalous animal behavior for very short time frames (within 2-3 days, usually hours) prior to a large seismic event (Kirschvink, 2000; Yokoi et al., 2003; Li et al., 2009).

Despite the large number of earthquake precursors reported in literature, most of which are summarized by Hartmann and Levy (2005); Cicerone et al. (2009), an International Commission on Earthquake Forecasting for Civil Protection concluded on 2 October 2009, "the search for precursors that are diagnostic of an impending earthquake has not yet produced a successful short-term prediction scheme" (ICEFCP, 2009). The reports of the International Association of Seismology and Physics of the Earth's Interior contain similar findings (Wyss and Booth, 1997). The lack of confidence can be attributed to several reasons. First, some fundamental aspects of many non-seismic signals, for example, lithosphere-atmosphere-ionosphere coupling and propagation of high-frequency electromagnetic signals in the conductive earth, are unresolved, and many of the proposed physical models are questionable (Uyeda et al., 2009). Second, the experimental data on precursory signals are often limited to few earthquakes and few measurement sites and they frequently contain gaps and different types of noise (Hartmann and Levy, 2005; Cicerone et al., 2009; Uyeda et al., 2009). Third, different techniques of identifying the anomalies are used for different signals or even in different studies for the same signal. In some cases, the anomalous changes are determined by analyzing the signals themselves (Hartmann and Levy, 2005; Uyeda et al., 2009; Cicerone et al., 2009), while in other cases they are identified by studying the derived statistics or functions, such as Fisher information or scaling parameters (Telesca et al., 2009a,b). Moreover, seasonal changes and instrumentation or other background noise often need to be filtered out prior to the identification of precursors.

In view of the above three problems, we believe that earthquake precursor research can be advanced by employing a phenomenological systems approach to the analysis of signals of different types in the same local geographic region. We assume that a large earthquake may be preceded by a system reconfiguration (preparation) on different time and space scales, which manifests itself in qualitative changes of various signals within relatively short time intervals. For example, such anomalous hydrogeochemical signals may be observed months to weeks before the impending earthquake, anomalous geoacoustic emissions - only days prior to the event, and anomalous behavior of animals only hours before the catastrophe. In order to test this approach and identify different signals that may be related to a specific large seismic event, one needs to have a standard criterion or a set of standard criteria to detect signal anomalies in virtually arbitrary signals. In this study, we will use a nonstationarity factor introduced within the framework of flicker-noise spectroscopy (FNS), a statistical physics approach to the analysis of time series (Timashev and Polyakov, 2007; Timashev, 2007; Timashev et al., 2010b). This dimensionless criterion is practically independent from the individual features of source signals and is designed to detect abrupt structural changes in the system generating the signal, which makes it a promising candidate to be one of the standard criteria. The nonstationarity factor was previously used to detect precursors in electrochemical and telluric signals recorded in the Garm area, Tajikistan prior to the large 1984 Dzhirgatal earthquake (Descherevsky et al., 2003; Vstovsky et al., 2005), geoelectrical signals at station Giuliano, Italy prior to several 2002 earthquakes (Telesca et al., 2004), and ULF geomagnetic data at Guam prior to the large 1993 Guam earthquake (Hayakawa and Timashev, 2006; Ida et al., 2007). Other approaches to identifying precursory features in earthquake- and volcano-related signals, which are based on different nonlinear analysis techniques, were discussed by Telesca et al. (2010, 2009a,b); Telesca and Lovallo (2009); Telesca et al. (2008).

In this study, we consider a combined analysis of two different types of signals, hydrogeochemical (sampling frequency from 3 to $6 \mathrm{day}^{-1}$ ) and geoacoustic (sampling frequency of $1 \mathrm{~min}^{-1}$ ), recorded on the Kamchatka peninsula, Russia.

\section{Nonstationarity factor}

Here, we will only deal with the basic FNS relations needed to understand the nonstationarity factor. The approach is described in detail elsewhere (Timashev, 2006; Timashev and Polyakov, 2007; Timashev, 2007; Timashev et al., $2010 b)$. The FNS procedures for analyzing original signal $V(t)$, where $t$ is time, are based on the extraction of information contained in autocorrelation function

$\psi(\tau)=\langle V(t) V(t+\tau)\rangle$,

where $\tau$ is the time lag parameter. The angular brackets in relation (1) stand for the averaging over time interval $T$ :

$$
\langle(\ldots)\rangle=\frac{1}{T} \int_{-T / 2}^{T / 2}(\ldots) d t .
$$


To extract the information contained in $\psi(\tau)$, the following transforms, or "projections", of this function are analyzed: cosine transforms (power spectrum estimates) $S(f)$, where $f$ is the frequency,

$S(f)=\int_{-T / 2}^{T / 2}\langle V(t) V(t+\tau)\rangle \cos \left(2 \pi f t_{1}\right) d t_{1}$

and its difference moments (Kolmogorov transient structural functions) of the second order $\Phi^{(2)}(\tau)$

$\Phi^{(2)}(\tau)=\left\langle[V(t)-V(t+\tau)]^{2}\right\rangle$.

To analyze the effects of nonstationarity in real processes, we study the dynamics of changes in $\Phi^{(2)}(\tau)$ for consecutive "window" intervals $\left[t_{k}, t_{k}+T\right]$, where $k=0,1,2,3$, and $t_{k}=k \Delta T$, that are shifted within the total time interval $T_{\text {tot }}$ of experimental time series $\left(t_{k}+T<T_{\text {tot }}\right)$. The time intervals $T$ and $\Delta T$ are chosen based on the physical understanding of the problem in view of the suggested characteristic time of the process, which is the most important parameter of system evolution. The phenomenon of "precursor" occurrence is assumed to be related to abrupt changes in functions $\Phi^{(2)}(\tau)$ when the upper bound of the interval $\left[t_{k}, t_{k}+T\right]$ approaches the time moment $t_{\mathrm{c}}$ of a catastrophic event accompanied by total system reconfiguration on all space scales.

The analysis of experimental stochastic series often requires the original data to be separated into smoothed and fluctuation components. In this study, we apply the "relaxation" procedure proposed by Timashev and Vstovskii (2003) based on the analogy with a finite-difference solution of the diffusion equation, which allows one to split the original signal into low-frequency $V_{R}(t)$ and high-frequency $V_{F}(t)$ components. The iterative procedure of finding the new values of the signal at every relaxation step using its values for the previous step allows one to determine the lowfrequency component $V_{R}(t)$. The high-frequency component $V_{F}(t)$ is obtained by subtracting $V_{R}(t)$ from the original signal. This smoothing algorithm progressively reduces the local gradients of the "concentration" variables, causing the points in every triplet to come closer to each other. Such splitting of the original signal $V(t)$ into $V_{R}(t)$ and $V_{F}(t)$ makes it possible to evaluate the nonstationarity factor for each of the three functions $V_{J}(t)(J=R, F$, or $G)$, where index $G$ corresponds to the original signal.

The FNS nonstationarity factor $C_{J}\left(t_{k}\right)$ is defined as

$$
\begin{aligned}
& C_{J}\left(t_{k}\right)=2 \cdot \frac{Q_{k}^{J}-P_{k}^{J}}{Q_{k}^{J}+P_{k}^{J}} \cdot \frac{T}{\Delta T}, \\
& Q_{k}^{J}=\frac{1}{\alpha T^{2}} \int_{0}^{\alpha T} \int_{t_{k}}^{t_{k}+T}\left[V_{J}(t)-V_{J}(t+\tau)\right]^{2} d t d \tau, \\
& P_{k}^{J}=\frac{1}{\alpha T^{2}} \int_{0}^{\alpha T} \int_{t_{k}}^{t_{k}+T-\Delta T}\left[V_{J}(t)-V_{J}(t+\tau)\right]^{2} d t d \tau .
\end{aligned}
$$

Here, $J$ indicates which function $V_{J}(t)(J=R, F$ or $G)$ is used. Expressions (6-7) are given in discrete form elsewhere (Timashev et al., 2010a). Note that functions $\Phi_{J}^{(2)}(\tau)$ can be reliably evaluated only on the $\tau$ interval of $[0, \alpha T]$, which is less than half of the averaging interval $T$; i.e., $\alpha<0.5$.

\section{Experimental data for the Kamchatka peninsula}

The data were recorded in the south-eastern part of the Kamchatka peninsula located in the Russian Far East. The eastern part of the peninsula is one of the most seismically active regions in the world. The area of highest seismicity localized in the depth range between 0 and $40 \mathrm{~km}$ represents a narrow stripe of land with the length of approximately $200 \mathrm{~km}$ along the east coast of Kamchatka, which is bounded by a deep-sea trench on the east (Fedotov et al., 1985).

Specialized measurements of underground water characteristics were started in 1977 to find and study hydrogeochemical precursors of Kamchatka earthquakes. Currently, the observation network includes four stations in the vicinity of Petropavlosk-Kamchatsky (Fig. 1). The Pinachevo station includes five water reservoirs: four warm springs and one borehole GK-1 with a depth of $1261 \mathrm{~m}$. The Moroznaya station has a single borehole No. 1 with a depth of $600 \mathrm{~m}$. The Khlebozavod station also includes a single borehole G-1 with a depth of $2540 \mathrm{~m}$, which is located in PetropavloskKamchatsky. The Verkhnyaya Paratunka station comprises four boreholes (GK-5, GK-44, GK-15, and GK-17) with depths in the range of 650 to $1208 \mathrm{~m}$.

The system of hydrogeochemical observations includes the measurement of atmospheric pressure and air temperature, measurement of water discharge and temperature of boreholes and springs, collection of water and gas samples for further analysis in laboratory environment. For water samples, the following parameters were determined: $\mathrm{pH}$; ion concentrations of chlorine $\left(\mathrm{Cl}^{-}\right)$, bicarbonate $\left(\mathrm{HCO}_{3}^{-}\right)$, sulfate $\left(\mathrm{SO}_{4}^{2-}\right)$, sodium $\left(\mathrm{Na}^{+}\right)$, potassium $\left(\mathrm{K}^{+}\right)$, calcium $\left(\mathrm{Ca}^{2+}\right)$, and magnesium $\left(\mathrm{Mg}^{2+}\right)$; concentrations of boric $\left(\mathrm{H}_{3} \mathrm{BO}_{3}\right)$ and silicone $\left(\mathrm{H}_{4} \mathrm{SiO}_{4}\right)$ acids. For samples of gases dissolved in water, the following concentrations are determined: methane $\left(\mathrm{CH}_{4}\right)$, nitrogen $\left(\mathrm{N}_{2}\right)$, oxygen $\left(\mathrm{O}_{2}\right)$, carbon dioxide $\left(\mathrm{CO}_{2}\right)$, helium $(\mathrm{He})$, hydrogen $\left(\mathrm{H}_{2}\right)$, hydrocarbon gases: ethane $\left(\mathrm{C}_{2} \mathrm{H}_{6}\right)$, ethylene $\left(\mathrm{C}_{2} \mathrm{H}_{4}\right)$, propane $\left(\mathrm{C}_{3} \mathrm{H}_{8}\right)$, propylene $\left(\mathrm{C}_{3} \mathrm{H}_{6}\right)$, butane $\left(\mathrm{C}_{4} \mathrm{H}_{10} \mathrm{n}\right)$, and isobutane $\left(\mathrm{C}_{4} \mathrm{H}_{10} \mathrm{i}\right)$. The data are recorded at nonuniform sampling intervals with one dominant sampling frequency. For the Pinachevo, Moroznaya, and Khlebozavod stations, this average sampling frequency is one measurement per 3 days; for the Verkhnyaya Paratunka station, one measurement per 6 days. Multiple studies of the hydrogeochemical data and corresponding seismic activity for the Kamchatka peninsula reported anomalous changes in the chemical and/or gas composition of underground waters prior to several large earthquakes in the time frame from 1987 to 2001 (Kopylova 


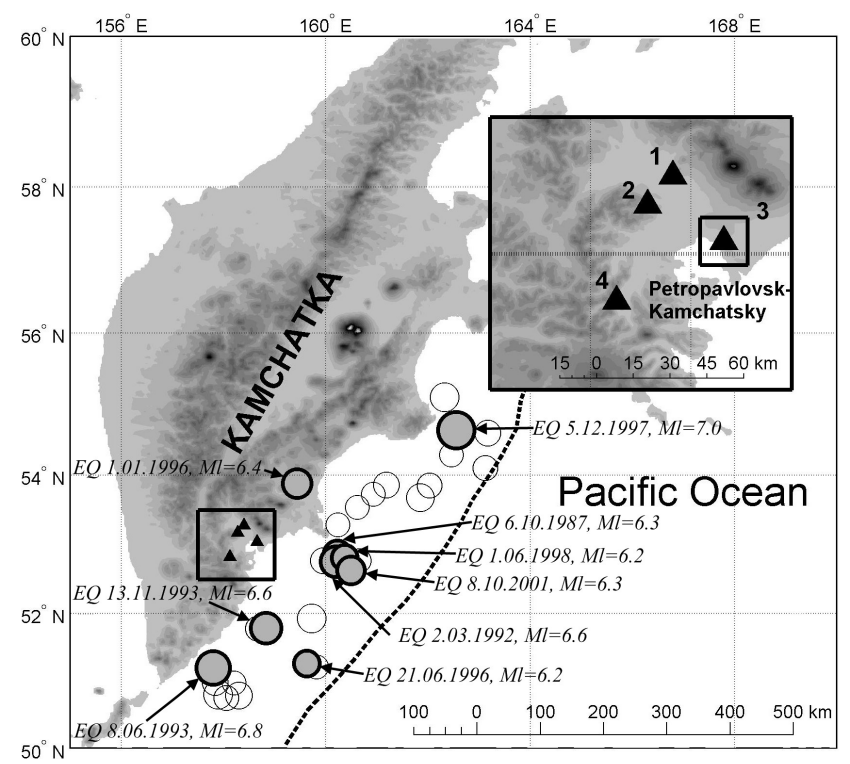

Fig. 1. Schematic of the measurement area (small rectangular frame on the left) and epicenters of largest earthquakes $\left(M_{1} \geq\right.$ $6, H \leq 50 \mathrm{~km}, D \leq 350 \mathrm{~km}$ ) from 1985 to 2009 , where $M_{1}-$ local earthquake magnitude, $H$ - depth, $D$ - distance from the epicenter. The large frame on the right shows a zoomed-in view of the positions of hydrogeological stations: 1 - Pinachevo, 2 - Moroznaya, 3 - Khlebozavod, 4 - Verkhnyaya Paratunka. The solid circles denote the earthquakes reportedly preceded by hydrogeochemical anomalies. The dashed line is the axis of the deep-sea trench. The earthquakes were selected using the catalog of Kamchatka Branch, Geophysical Survey of Russian Academy of Sciences.

et al., 1994; Bella et al., 1998; Biagi et al., 2000, 2006; Khatkevich and Ryabinin, 2006). In this study, we analyze the variations of chlorine-ion concentration determined by a titrimetric method (relative error from 1 to $10 \%$ ).

Geoacoustic emissions in the frequency range from 25 to $1400 \mathrm{~Hz}$ ( 0.7 level) have also been recorded in the deep G-1 borehole of the Khlebozavod station under the supervision of V. A. Gavrilov since August 2000. The data analyzed in this paper were obtained by a geophone with crystal ferromagnetic sensors (Belyakov, 2000). The output signal of such a sensor is proportional to the third derivative of ground displacement, and the gain slope is $60 \mathrm{~dB}$ per decade of frequency change. The geophone was set up at a depth of $1035 \mathrm{~m}$, which is enough to reduce anthropogenic noise levels by more than two orders of magnitude (Gavrilov et al., 2008). The geophone body was fixed inside the borehole casing by a spring. The vertical channel sensitivity of the geophone is $0.15 \mathrm{~V} \mathrm{~s}^{3} \mathrm{~m}^{-1}$. The sensitivity of horizontal channels is $0.60 \mathrm{~V} \mathrm{~s}^{3} \mathrm{~m}^{-1}$. The sensor output signals are separated by third-octave band pass filters into four frequency bands with central frequencies 30, 160, 560, and $1200 \mathrm{~Hz}$, which is followed by real-time hardware/software signal processing. The value of the postprocessed output signal for each channel is proportional to the average value of the input signal for one-minute intervals. A more detailed description of geoacoustic emission observations and experimental setup for the G-1 borehole is presented elsewhere (Gavrilov et al., 2008).

\section{Results}

To illustrate the nonstationarity factor and proposed phenomenological method, we have analyzed the hydrogeochemical data for chlorine-ion concentrations at GK1 (Pinachevo station) and GK-44 (Verkhnyaya Paratunka station) and geoacoustic emissions at the output of geophone vertical frequency channel with the central frequency of $160 \mathrm{~Hz}$ (Z160) in G-1 (Khlebozavod station). Chlorineion concentration time series for GK-1 (Cl-GK1) was selected because it is characterized by a unidirectional longperiod trend without seasonal variations (Fig. 2) and was already treated as a precursory signal due to a gradual chlorine-ion concentration decline down to a local minimum from 30 to 60 days before several earthquakes (Khatkevich and Ryabinin, 2006). On the other hand, chlorine-ion concentration at GK-44 (Cl-GK44) is not considered as a precursory signal because it is dominated by seasonal concentration changes on the background of a slowly varying local mean, the minimum value of which was reached shortly after the strong earthquake on 5 December $1997\left(M_{1}=\right.$ 7.0). The Z160 signal was selected from the whole set of geoacoustic time series because it contains the lowest level of noise (highest signal-to-noise ratio).

To keep the statistical structure of source time series practically intact, the signals were subjected only to minimal preprocessing, which included the removal of single-point spikes, reduction of the hydrogeochemical time series to uniform sampling intervals using linear interpolations, and the extraction of every 30th point in the geoacoustic time series to form a new time series with the frequency of $30 \mathrm{~min}^{-1}$. Then the time series $V_{G}(t)$ were divided into low-frequency $V_{R}(t)$ and high-frequency $V_{F}(t)$ components, which were used to calculate the nonstationarity factors. In evaluating $C_{J}(J=R, F$ or $G)$ for the hydrogeochemical series, averaging time intervals $T$ in the range from 50 to 900 days were used. For the geoacoustic time series, the interval $T$ was varied from 3 to 20 days. Our analysis showed that the values of $T$ equal to 600 and 20 days are most adequate for locating precursors in the hydrogeochemical and geoacoustic series, respectively.

Figures 2 and 3 show the variations of $C_{J}$ for $\mathrm{Cl}-$ GK1 and Gl-CK44 together with largest seismic events. It can be seen that spikes in $C_{J}$ precede several large earthquakes. It should be noted that the low-frequency component $C_{R}$ shows the most number of precursors for ClGK1 and high-frequency component is most informative for $\mathrm{Cl}-\mathrm{CK} 44$. The first fact is in agreement with the study of 


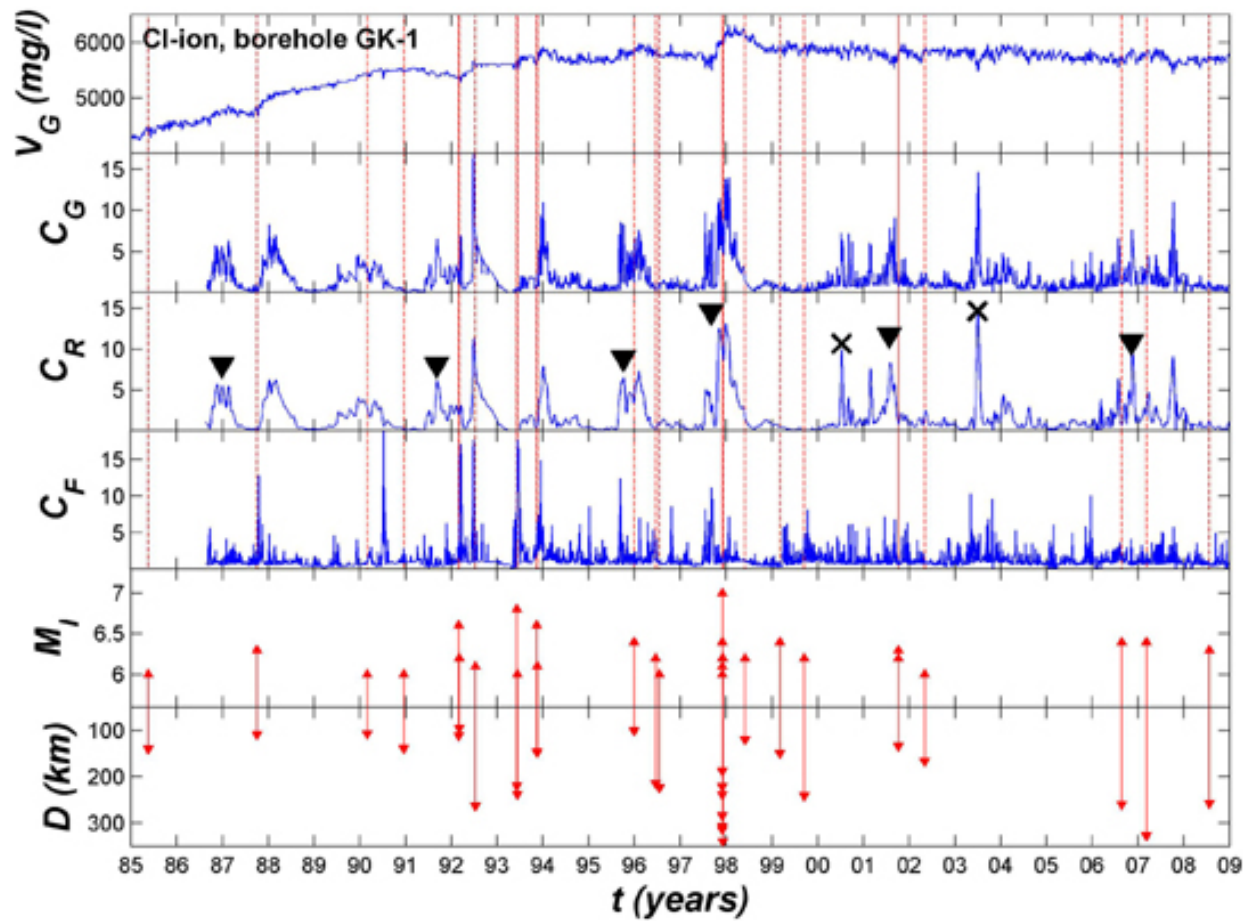

Fig. 2. Comparison of nonstationarity factor $C_{J}(T=600$ days, $\Delta T=3$ days $)$ for the GK-1 chlorine-ion concentration time series with seismic activity: $V_{G}$ - source signal; $C_{G}$ - nonstationarity factor for $V_{G}, C_{R}$ - nonstationarity factor for the low-frequency component of $V_{G}, C_{F}$ - nonstationarity factor for the high-frequency component of $V_{G}, M_{1}$ - local earthquake magnitude, $D$ - distance from the epicenter. Solid triangles denote sample $C_{R}$ spikes preceding large earthquakes. Crosses denote sample $C_{R}$ spikes not related to large seismic events.

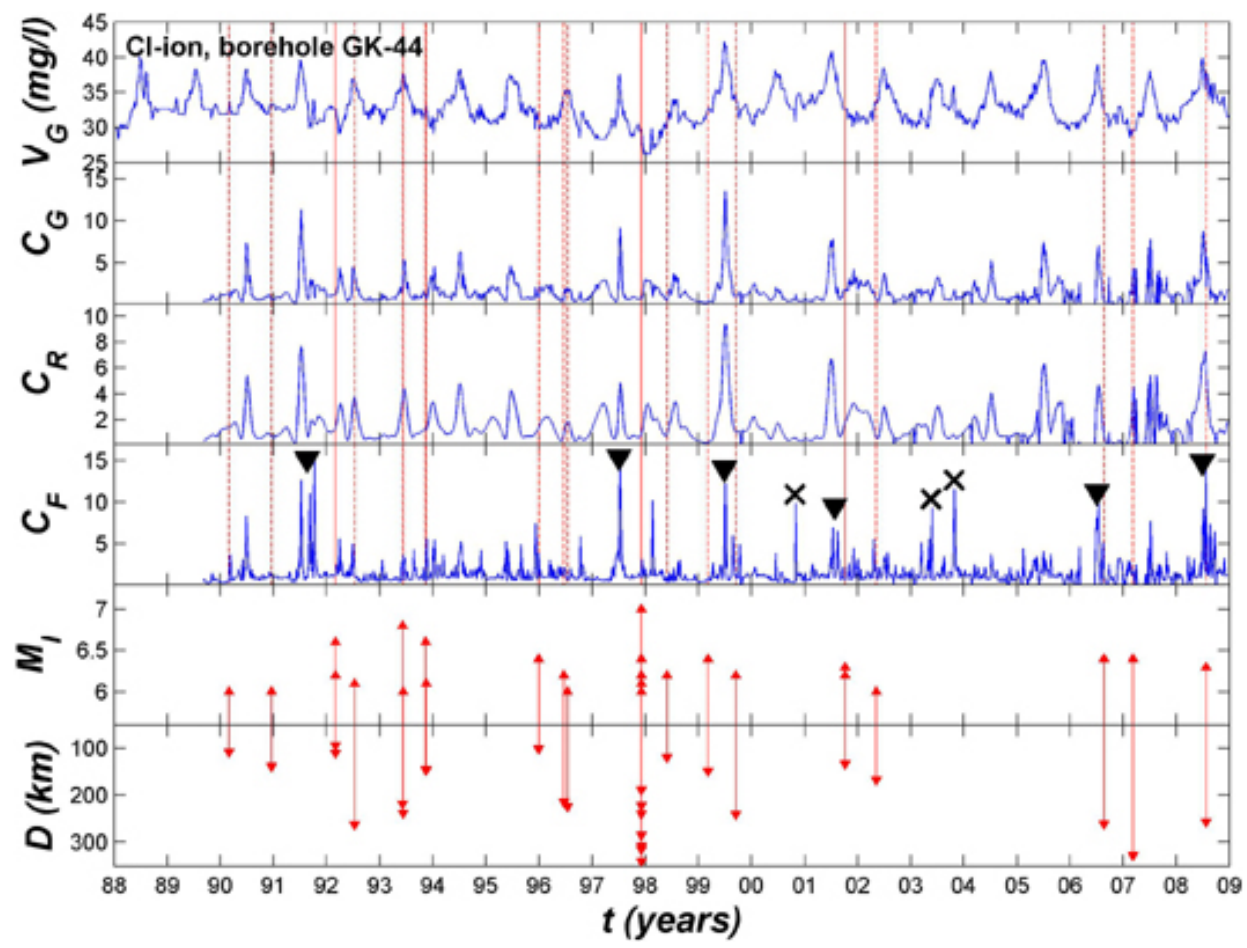

Fig. 3. Comparison of nonstationarity factor $C_{J}$ ( $T=600$ days, $\Delta T=3$ days) for the GK- 44 chlorine-ion concentration time series with seismic activity: Nomenclature as in Fig. 2. Solid triangles denote sample $C_{F}$ spikes preceding large earthquakes. Crosses denote sample $C_{F}$ spikes not related to large seismic events. 


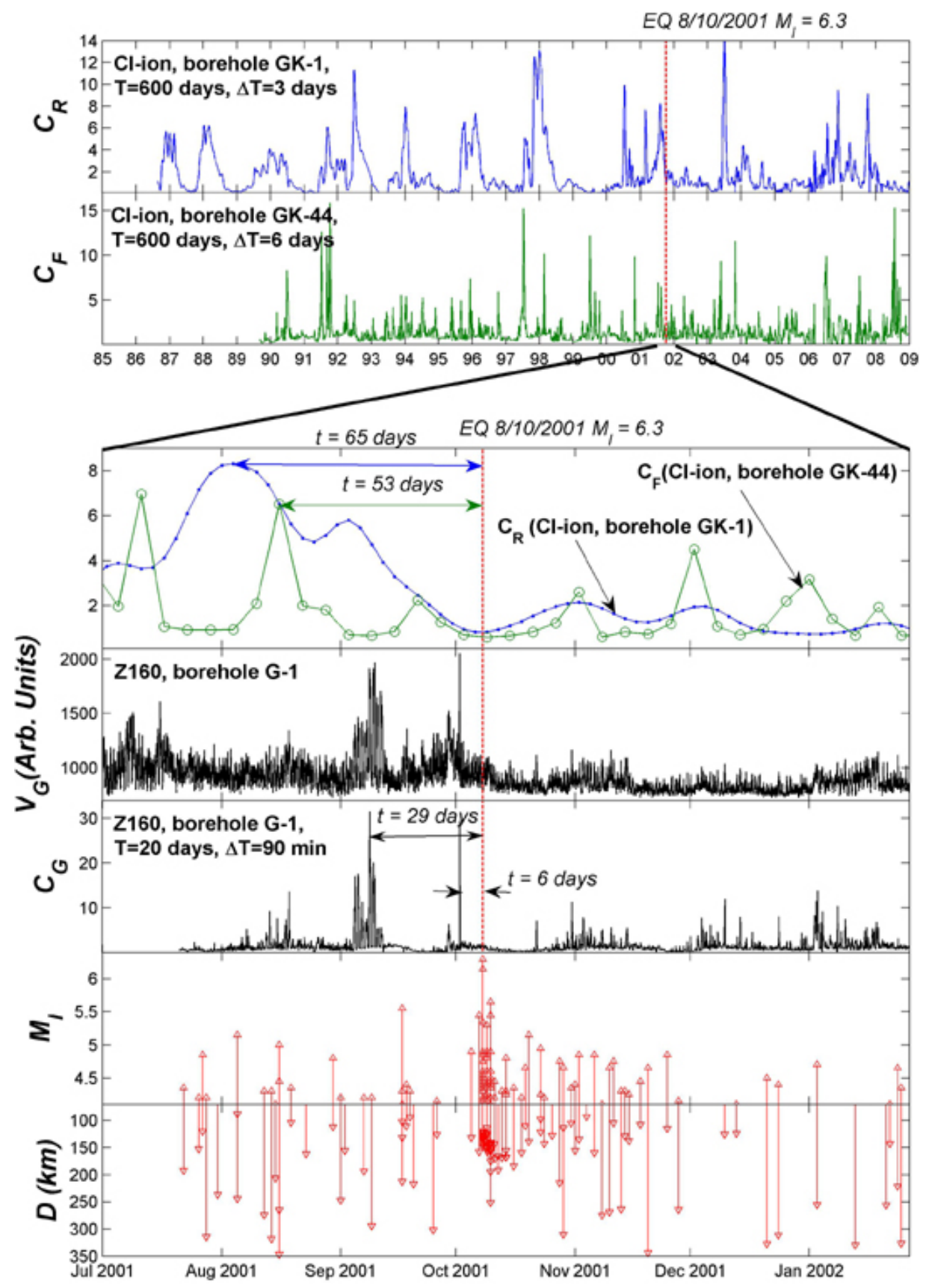

Fig. 4. Nonstationarity factors for GK-1 and GK-44 chlorine-ion concentrations and Z160 G-1 geoacoustic emissions in a time frame around the 8 October 2001 earthquake. $M_{1}$ - local earthquake magnitude, $D$ - distance from the epicenter. The double-headed arrows denote the time intervals between the nonstationarity factor spikes and earthquake itself.

Khatkevich and Ryabinin (2006). The second fact implies that the use of the high-frequency component eliminated seasonal changes from the analysis and made Cl-GK44 a precursory signal. Therefore, the FNS nonstationarity factor together with the procedure for separating out highfrequency and low-frequency signal components can be used to analyze different signals despite major differences in their specific features.
Figure 4 shows a combined analysis of hydrogeochemical and geoacoustic variations in a time frame around the 8 October 2001 earthquake $\left(M_{1}=6.3, H=24 \mathrm{~km}, D=\right.$ $134 \mathrm{~km}$ from Petropavlovsk-Kamchatsky), which was the strongest earthquake (based on local magnitude and distance to the epicenter) recorded for the whole time interval of geoacoustic observations in the G-1 borehole. Nonstationarity factors $C_{R}$ for $\mathrm{Cl}-\mathrm{GK} 1$ and $C_{F}$ for Cl-GK44 show spikes 
with highest values (precursors) in a time frame of 50 to 70 days before the earthquake. $C_{G}$ for G-1 (the signal is a high-frequency one by its nature) shows precursors 29 and 6 days before the event, which is in agreement with the results reported by Gavrilov et al. (2008). In other words, anomalous changes in the geoacoustic signals happen closer to the earthquake than in the hydrogeochemical ones, which implies that precursory signals of different nature may take place on different timescales before a large earthquake.

\section{Conclusions}

The above example shows that precursory signals of different types may be observed in the same local seismically active zone at different times prior to a large earthquake; these may be attributed to some system preparation preceding the seismic event. In the case studied, the qualitative changes may be related to a system-wide structural medium reconfiguration in the preparatory phase of the earthquake.

This study also shows that the FNS nonstationarity factor can be used as the standard criterion to detect qualitative changes within relatively short time intervals in virtually arbitrary signals, even if the signals contain strongly pronounced periodic components, as was the case for $\mathrm{Cl}$ CK44. It should be noted that the nonstationarity factor should be analyzed not only for the original signal, but also for its smoothed (low-frequency) and fluctuation (highfrequency) components.

In order to validate the proposed phenomenological systems approach, comprehensive monitoring of seismically active regions such as the Kamchatka peninsula should be performed and the data should be analyzed with the FNS nonstationarity factor. The measured characteristics should include geoacoustic, hydrological/hydrochemical, gasgeochemical, geodetic, and electromagnetic signals summarized in the introduction.

Acknowledgements. This study was supported in part by the Russian Foundation for Basic Research, project nos. 09-05-98543 and 10-02-01346.

Edited by: K. Eftaxias

Reviewed by: L. Telesca and another anonymous referee

\section{References}

Bella, F., Biagi, P. F., Caputo, M., Cozzi, E., Monica, G. D., Ermini, A., Gordeez, E. I., Khatkevich, Y. M., Martinelli, G., Plastino, W., Scandone, R., Sgrigna, V., and Zilpimiani, D.: Hydrogeochemical anomalies in Kamchatka (Russia), Phys. Chem. Earth, 23, 921-925, 1998.

Belyakov, A. S.: Magnetoelastic acoustic geophones for geophysical research and earthquake prediction, Seismicheskie Pribory, 33, 27-45, 2000 (in Russian).
Biagi, P. F., Ermini, A., Cozzi, E., Khatkevich, Y. M., and Gordeev, E. I.: Hydrogeochemical precursors in Kamchatka (Russia) related to the strongest earthquakes in 1988-1997, Nat. Hazards, 21, 263-276, 2000.

Biagi, P. F., Castellana, L., Minafra, A., Maggipinto, G., Maggipinto, T., Ermini, A., Molchanov, O., Khatkevich, Y. M., and Gordeev, E. I.: Groundwater chemical anomalies connected with the Kamchatka earthquake $(M=7.1)$ on March 1992, Nat. Hazards Earth Syst. Sci., 6, 853 - 859, doi:10.5194/nhess-6-8532006, 2006.

Cicerone, R. D., Ebel, J. E., and Britton, J.: A systematic compilation of earthquake precursors, Tectonophysics, 476, 371-396, 2009.

Descherevsky, A. V., Lukk, A. A., Sidorin, A. Y., Vstovsky, G. V., and Timashev, S. F.: Flicker-noise spectroscopy in earthquake prediction research, Nat. Hazards Earth Syst. Sci., 3, 159-164, doi:10.5194/nhess-3-159-2003, 2003.

Du, J., Amita, K., Ohsawa, S., Zhang, Y., Kang, C., and Yamada, M.: Experimental evidence on formation of imminent and short-term hydrochemical precursors for earthquakes, Appl. Geochem., 25, 586-592, 2010.

Fedotov, S. A., Gusev, A. A., Shumilina, L. S., and Chernyshova, V. G.: The seismofocal zone of Kamchatka, Volkanologiya i Seismologiya, 91-107, 1985 (in Russian).

Gavrilov, V., Bogomolov, L., Morozova, Y., and Storcheus, A.: Variations in geoacoustic emissions in a deep borehole and its correlation with seismicity, Ann. Geophys.-Italy, 51, 737-753, 2008.

Geller, R. J.: Earthquake prediction: a critical review, Geophys. J. Int., 131, 425-450, 1997.

Geller, R. J., Jackson, D. D., Kagan, Y. Y., and Mulargia, F.: Earthquakes cannot be predicted, Science, 275, 1616-1617, 1997.

Gordienko, V., Gordienko, T., Krasnopistsev, N., Kuptsov, A., Larionov, I., Marapulets, Y., Rutenko, A., and Shevtsov, B.: Anomaly in high-frequency geoacoustic emission as a close earthquake precursor, Acoust. Phys., 54, 82-93, 2008.

Hartmann, J. and Levy, J. K.: Hydrogeological and gasgeochemical earthquake precursors - A review for application, Nat. Hazards, 34, 279-304, 2005.

Hayakawa, M. and Timashev, S. F.: An attempt to find precursors in the ULF geomagnetic data by means of flicker noise spectroscopy, Nonlin. Processes Geophys., 13, 255-263, doi:10.5194/npg-13-255-2006, 2006.

ICEFCP: Operational Earthquake Forecasting: State of Knowledge and Guidelines, available at: http://www.iaspei.org/downloads/ Ex_Sum_v5_THJ9_A4format.pdf (last access: 1 October 2010), 2009.

Ida, Y., Hayakawa, M., and Timashev, S.: Application of different signal analysis methods to the ULF data for the 1993 Guam earthquake, Nat. Hazards Earth Syst. Sci., 7, 479-484, doi:10.5194/nhess-7-479-2007, 2007.

Ihmle, P. and Jordan, T.: Teleseismic search for slow precursors to large earthquakes, Science, 266, 1547-1551, 1994.

Khatkevich, Y. and Ryabinin, G.: Geochemical an ground-water studies in Kamchatka in the search for earthquakes precursors, Vulkanologiya i Seysmologiya, 4, 34-42, 2006 (in Russian).

Kirschvink, J. L.: Earthquake prediction by animals: Evolution and sensory perception, B. Seismol. Soc. Am., 90, 312-323, 2000. 
Kopylova, G., Sugrobov, V., and Khatkevich, Y.: Variations in the regime of springs and hydrogeological boreholes in the Petropavlovsk polygon (Kamchatka) related to earthquakes, Vulkanologiya i Seysmologiya, 2, 53-70, 1994 (in Russian).

Li, Y., Liu, Y., Jiang, Z., Guan, J., Yi, G., Cheng, S., Yang, B., $\mathrm{Fu}, \mathrm{T}$., and Wang, Z.: Behavioral change related to Wenchuan devastating earthquake in mice, Bioelectromagnetics, 30, 613620, 2009.

Reasenberg, P. A.: Foreshock occurrence before large earthquakes, J. Geophys. Res., 104, 4755-4768, 1999.

Telesca, L. and Lovallo, M.: Non-uniform scaling features in central Italy seismicity: A non-linear approach in investigating seismic patterns and detection of possible earthquake precursors, Geophys. Res. Lett., 36, L01308, doi:10.1029/2008GL036247, 2009.

Telesca, L., Lapenna, V., Timashev, S., Vstovsky, G., and Martinelli, G.: Flicker-noise spectroscopy: a new approach to investigate the time dynamics of geoelectrical signals measured in seismic areas, Phys. Chem. Earth., 29, 389-395, 2004.

Telesca, L., Lapenna, V., Macchiato, M., and Hattori, K.: Investigating non-uniform scaling behavior in Ultra Low Frequency (ULF) earthquake-related geomagnetic signals, Earth Planet. Sci. Lett., 268, 219-224, 2008.

Telesca, L., Lovallo, M., Ramirez-Rojas, A., and Angulo-Brown, F.: A nonlinear strategy to reveal seismic precursory signatures in earthquake-related self-potential signals, Physica A, 388, 20362040, 2009a.

Telesca, L., Lovallo, M., Ramirez-Rojas, A., and Angulo-Brown, F.: Scaling instability in self-potential earthquake-related signals, Physica A, 388, 1181-1186, 2009 b.

Telesca, L., Lovallo, M., and Carniel, R.: Time-dependent Fisher Information Measure of volcanic tremor before the 5 April 2003 paroxysm at Stromboli volcano, Italy, J. Volcanol. Geoth. Res., 195, 78-82, 2010.

Timashev, S. F.: Flicker noise spectroscopy and its application: Information hidden in chaotic signals, Russ. J. Electrochem., 42, 424-466, 2006.
Timashev, S. F.: Fliker-Shumovaya Spektroskopiya: Informatsiya v khaoticheskikh signalakh (Flicker-Noise Spectroscopy: Information in Chaotic Signals), Fizmatlit, Moscow, 2007.

Timashev, S. F. and Polyakov, Y. S.: Review of flicker noise spectroscopy in electrochemistry, Fluct. Noise Lett., 7, R15R47, doi:10.1142/S0219477507003829, 2007.

Timashev, S. F. and Vstovskii, G. V.: Flicker-noise spectroscopy for analyzing chaotic time series of dynamic variables: Problem of signal-to-noise relation, Russ. J. Electrochem., 39, 141-153, 2003.

Timashev, S. F., Polyakov, Y. S., Lakeev, S. G., Misurkin, P., and Danilov, A.: Fundamentals of fluctuation metrology, Russ. J. Phys. Chem. A, 84, 1807-1825, 2010a.

Timashev, S. F., Polyakov, Y. S., Misurkin, P. I., and Lakeev, S. G.: Anomalous diffusion as a stochastic component in the dynamics of complex processes, Phys. Rev. E, 81, 041128, doi:10.1103/PhysRevE.81.041128, 2010b.

Uyeda, S., Nagao, T., and Kamogawa, M.: Short-term earthquake prediction: Current status of seismo-electromagnetics, Tectonophysics, 470, 205-213, 2009.

Vstovsky, G. V., Descherevsky, A. V., Lukk, A. A., Sidorin, A. Y., and Timashev, S. F.: Search for electric earthquake precursors by the method of Flicker-noise spectroscopy, Izv.-Phys. Soild Earth, 41, 513-524, 2005.

Wyss, M. and Booth, D. C.: The IASPEI procedure for the evaluation of earthquake precursors, Geophys. J. Int., 131, 423424, 1997.

Wyss, M., Aceves, R. L., Park, S. K., Geller, R. J., Jackson, D. D., Kagan, Y. Y., and Mulargia, F.: Cannot earthquakes be predicted?, Science, 278, 487-490, 1997.

Yokoi, S., Ikeya, M., Yagi, T., and Nagai, K.: Mouse circadian rhythm before the Kobe earthquake in 1995, Bioelectromagnetics, 24, 289-291, 2003. 